\title{
Treatment of Alzheimer's Disease: Hopes and Reality
}

\author{
S. Gauthier, L. Gauthier, R. Bouchard, R. Quirion and S. Sultan
}

\begin{abstract}
The relative failure of symptomatic therapeutic trials for Alzheimer's disease using non-selective cholinergic agonists brings about the need for longitudinal studies with parallel designs aimed at disease stabilization, using trophic substances or amyloid suppressors.
\end{abstract}

RÉSUMÉ: Traitement de la maladie d'Alzheimer: espoirs et réalités. L'échec relatif des essais thérapeutiques symptomatiques pour la maladie d'Alzheimer, basés sur des agonistes cholinergiques non sélectifs, nous amène à considérer des études longitudinales avec groupes parallèles visant à la stabilisation de la maladie, par l'usage de facteurs trophiques ou de suppresseurs de la substance amyloïde.

Can. J. Neurol. Sci. 1991; 18:439-44I

The recognition of a deficit in acetylcholine (Ach) levels in neocortical and hippocampal regions has led to a growing interest in the pharmacological treatment of Alzheimer's disease (AD). Although not unique among the neuro-transmitters, this deficit occurs early in the disease as shown by frontal cortical biopsies $^{1}$ and predominates in the neurochemical pathology of $\mathrm{AD}$ at autopsy. ${ }^{2}$ It is presumed to result from a progressive loss of cholinergic pre-synaptic elements deriving from cells located in the nucleus basalis of Meynert. ${ }^{3}$ Post-synaptic elements appear to be relatively spared, as shown by a proportionally greater loss of $\mathrm{M}_{2}$ presynaptic receptors compared to $\mathrm{M}_{1}$ postsynaptic sites. ${ }^{2}$ These observations have led to strategies aimed at the relief of targeted symptoms of AD through Ach precursor loading, nonselective muscarinic agonists and acetylcholinesterase blockers (Table 1). This review is a critical appraisal of these strategies in terms of trial designs, outcome variables, clinical significance, and global perspective on the treatment of AD. This material has been presented in part at the 2 nd International Conference on Alzheimer's disease and Related Disorders, Toronto, Ontario, July 1990.

\section{Trial Designs: Cross-Over or Parallel Groups?}

The relative strengths and weaknesses of cross-over and parallel designs for drug trials in general have been discussed by Louis et al. 7,8 On the basis of our recent experience with drug trials in AD (Table 1), the following comments can be made: cross-over trials offer the advantages that (1) all patients have an opportunity to receive the active treatment under double-blind conditions, (2) the comparison of results is made within one group of subjects rather than between two or more potentially heterogeneous groups, (3) the number of subjects required to reach statistically significant differences is small compared to parallel trials. However, disadvantages of cross-over designs are
(1) the potential carry-over effects between treatment blocks even with prolonged wash-out periods, (2) the longer duration because of the necessity of having treatment blocks in sequence, with the inevitable deterioration of patients' performances over time, as well as further attrition from various causes. The alternative is a parallel group design but this requires a large number of subjects and one group receives only placebo for the entire duration of the study (traditionally this group is offered the active treatment in an open follow-up design).

In a recent study 6 we reported a carry-over effect even after 4 week wash-out period, and we were able to measure the deterioration of AD subjects' performances in areas of cognition, functional autonomy and behavior over a period as short as 9 months. In view of these methodological problems we recommend that parallel group designs be implemented in future therapeutic trials for AD.

\section{Outcome Variables}

$\mathrm{AD}$ is a complex disease bringing about cognitive, functional, mood, behavioral and neurophysiological changes. Valid and reliable scales and techniques already exist for measuring some components of this syndrome. However there are factors limiting their use, such as (1) the low tolerance of subjects to lengthy testing procedures, (2) the lack of availability of alternate versions of tests for repeated measurements, (3) the paucity of validated translations of tests in order to enroll subjects of different ethnic groups, (4) the imprecision of staging of AD (since different stages show different patterns of symptoms and require different tests), (5) the ceiling and floor effects in most scales. Recognition of these limitations should encourage investigators to develop appropriate new instruments or to guide their selection of those already available for symptomatic trials in $\mathrm{AD}$. 
Table 1: Examples of Symptomatic Cholinergic Trials for Alzheimer's Disease

\begin{tabular}{lllc}
\hline Agents & Rationale & Design & References \\
\hline Lecithin & Precursor loading & $\begin{array}{l}\text { cross-over } \\
3 \text { mos/3 mos }\end{array}$ & 4 \\
Bethanechol & $\begin{array}{l}\text { Non-selective } \\
\text { muscarinic agonist }\end{array}$ & $\begin{array}{l}\text { cross-over } \\
3 \text { mos/3mos }\end{array}$ & 5 \\
$\begin{array}{l}\text { Tetrahydro } \\
\text { aminoacridine }\end{array}$ & $\begin{array}{l}\text { Acetylcholinesterase } \\
\text { inhibition }\end{array}$ & $\begin{array}{l}\text { cross-over } \\
2 \text { mos/2 mos } \\
\text { with 1 mo washout }\end{array}$ & 6 \\
\hline
\end{tabular}

Table 2: Examples of Scales and Tests Used in Longitudinal Studies of Alzheimer's Disease

\begin{tabular}{lc}
\hline References & \\
\hline Blessed Information - Memory - Concentration & 10 \\
Blessed Dementia Rating Scale & 11 \\
Boston Diagnostic Aphasia Examination & 12 \\
Boston Naming Test & 13 \\
Electroencephalography & 14 \\
Hierarchic Dementia Scale & 15 \\
Mini Mental State & 16 \\
Rapid Disability Rating Scale-II & 17 \\
Regional Cerebral Metabolic Rates for Glucose & 18 \\
Wechsler Memory Scale, Logical Memory &
\end{tabular}

Trials aiming at stabilization of disease progression will require longitudinal parallel designs in which variables known to change over the time frame of the study ( 1 to 2 years) are measured serially. Examples of some scales used to measure such variables are listed in Table 2. Differences between treated and untreated groups (comparable for all disease characteristics at the onset of the trial) would be analyzed statistically at the end of the study period. Another approach is the method of survival studies and the cumulative probability of reaching a clinical end-point similar, for example, to the need for L-Dopa therapy in early Parkinson's disease (PD). ${ }^{19}$ Potential end-points for AD could be loss of independence in activities of daily living, urinary incontinence and institutionalization. ${ }^{20}$ None of these are ideal and an index of deterioration may have to be designed specifically for $A D$ taking into account the variability of its course and the heterogeneity of its manifestations.

\section{Clinical Significance}

Considering our limited knowledge of the pathophysiology of $\mathrm{AD}$ and of correlation between observed biochemical/neuropathological changes and clinical symptoms, the development of a drug or treatment having a "Lazarus effect" (i.e. dramatic reversal of existing symptoms) is unlikely, at least in the foreseeable future.

What, then, would constitute a clinically significant effect in the pharmacologic treatment of AD? We feel that a measurable and sustained improvement in cognition and functional autonomy or behaviour in subjects receiving active treatment compared to those on placebo is essential for short-term symptomatic studies, whereas a measurable reduction in the expected deterioration in scores for relevant variables would be essential for long-term stabilization studies.

Should a treatment be made available to the general population of AD patients outside of research protocols if only a subgroup of responders is found to fulfill criteria for clinical significance? We feel that this should be the case only if the treatment is non-toxic and clear indications exist as to the doses and duration of therapy required for clinical use under less rigidly controlled conditions.

\section{Global Perspective for Treatment of AD}

Monotherapy with non-selective cholinergic agonists for $A D$ has not brought about clinical effects as significant as L-Dopa did for early PD. Perhaps this is because of the complexity of the human mind compared to muscle tone and kinesia, the severity of pathology in AD by the time symptoms become clinically detectable, and the multiplicity of transmitter systems involved. Our hopes for reaching "clinical significance" in symptomatic therapeutic trials for AD have thus be be realigned with reality.

That reality might include the need to address the issue of stabilization of $A D$ before finding symptomatically effective treatments. Nerve growth factor and other trophic factors are potential candidates in that regard. Moreover, agents interfering with $\beta$-amyloid deposition may also be available in the near future.

The variety of cross-cultural and trans-national neuro-epidemiology studies now underway will likely lead to the recognition of risk factors for the development of AD. The additional recognition of protective factors could lead to the development of preventive strategies such as those that have been successful in the treatment of stroke.

\section{ACKNOWLEDGEMENTS}

The authors research projects are funded by the Alzheimer Society of Canada, The American Health Assistance Foundation, the Fonds de la Recherche en Santé du Québec (FRSQ), the Medical Research Council of Canada. R. Quirion is holder of a "Chercheur-Boursier" award from the FRSQ. The expert secretarial assistance of Mrs. L. Jean-Morrison is acknowledged.

\section{REFERENCES}

1. Gauthier S, Leblanc R, Quirion R, et al. Transmitter-replacement therapy in Alzheimer's disease using intracerebro-ventricular infusions of receptors agonists. Can J Neurol Sci 1986; 13: 394-402.

2. Quirion R, Martel JC, Robitaille Y, et al. Neurotransmitter and receptor deficits in senile dementia of the Alzheimer type. Can J Neurol Sci 1986; 13: 503-510.

3. Doucette R, Fisman M, Hachinski NC, et al. Cell loss from the Nucleus Basalis of Meynert in Alzheimer's disease. Can J Neurol Sci 1986; 13: 435-440.

4. Etienne P, Dastoor D, Gauthier S, et al. Alzheimer disease: lack of effect of lecithin treatment for 3 months. Neurology 1981; 31: $1552-1554$

5. Harbaugh RE, Reeder TM, (Leblanc R), et al. Intracerebroventricular bethanechol chloride infusion in Alzheimer's disease. $J$ Neurosurg 1989; 71: 481-486.

6. Gauthier S, Bouchard R, Lamontagne A, et al. Tetrahydroaminoacridine-lecithin combination treatment in patients with intermediate - stage Alzheimer's disease. N Engl J Med 1990; 322: 1272-1276. 
7. Lavori PW, Louis TA, Bailar JC, et al. Designs for experiments parallel comparisons of treatment. N Engl J Med 1983; 309 1291-1298.

8. Louis TA, Lavori PW, Bailar JC, et al. Cross-over and self controlled designs in clinical research. N Engl J Med 1984; 310: 24-31.

9. Katzman R, Brown T, Thal LJ, et al. Comparison of rate of annual change of mental status score in four independent studies of patients with Alzheimer's disease. Ann Neurol 1988; 24: 384-389.

10. Stern Y, Hesdorffer D, Sano M, et al. Measurement and prediction of functional capacity in Alzheimer's disease. Neurology 1990; 40: 8-14.

11. Kaszniak AW, Wilson RS, Fox JH, et al. Cognitive assessment in Alzheimer's disease: Cross-sectional and longitudinal perspectives. Can J Neurol Sci 1986; 13: 420-423.

12. Huff FJ, Belle SH, Shin YK, et al. Prevalence and prognostic value of neurologic abnormalities in Alzheimer's disease. Dementia 1990; $1: 32-40$

13. Crapper McLachlan D, Dalton AJ, Galin H, et al. Alzheimer's disease: clinical course and cognitive disturbances. Acta Neurol Sand 1984; 60 suppl 99: 83-88.

14. Dastoor D, Cole MG. The course of Alzheimer's disease: an uncontrolled longitudinal study. J Clin Exp Gerontology 1985-86; 7 : 289-299.
15. Uhlamnn RF, Larson EB, Buchner DM. Correlations of MiniMental State and Modified Dementia Rating Scale to measure transitional health status in dementia. J Gerontology 1987; 42: 33-36.

16. Gauthier L, Gauthier S. Assessment of functional changes in Alzheimer's disease. Neuroepidemiology 1990; 9: 183-188.

17. Grady CL, Haxby JV, Horwitz B, et al. Longitudinal study of the early neuropsychological and cerebral metabolic changes in dementia of the Alzheimer type. J Clin Exp Neuropsychology 1988; 10: 576-596.

18. Botwinick J, Storandt M, Berg L. A longitudinal behavioral study of senile dementia of the Alzheimer type. Arch Neurol 1986; 43: 1124-1127.

19. The Parkinson Study Group. Effect of Deprenyl on the progression of disability in early Parkinson's disease. N Engl J Med 1989; 321: 1364-1371.

20. Drachman DA, O'Donell BF, Lew RA, et al. The prognosis in Alzheimer's disease: how far rather than how fast best predicts the course. Arch Neurol 1990; 47: 851-856. 